\title{
Focusing Early Phases in Production System Design
}

\author{
Carin Rösiö and Jessica Bruch \\ Mälardalen University, School of Innovation, Design and Engineering, Eskilstuna, Sweden \\ \{Carin.rosio, Jessica.bruch\}@mah.se
}

\begin{abstract}
It is a well-known fact that it is in the early phases of production system design where the most important decisions are made. If the production system is not designed in a proper way, this will eventually end up with disturbances and problems during serial production and it is in the early phases the potential to influence is greatest. The purpose with this paper is therefore to describe how to work and what activities to focus on in early phases of production system design by proposing a structured production system design model focusing on the early phases which can be applied by practitioners and academics. Six production system design projects were studied in three real-time case studies and three retrospective case studies. Combined with literature studies a production system design model is developed describing the initial phases of initiation, project definition and concept including activities and decision points.
\end{abstract}

Keywords: Production system design, manufacturing industry, early phases

\section{Introduction}

There is an increasing need for efficient production system design due to the fact that manufacturing companies must be able to handle issues such as increasing individualization of customer demands, fluctuating consumption and permanent pressure on product cost and quality [1]. European manufacturing companies have a high standard and a strong position in industrial engineering with innovative and customized product solutions, however, they lose market shares in mass production [2]. Attractive product solutions are not enough, a successful production activity is also required in order to be competitive. The potential of an effective production system design process is often not prioritized enough in manufacturing companies even though it is shown that a number of competitive advantages can be achieved such as fast ramp up, shorter time to market, robust production systems, increased market shares, higher customer acceptance, improved levels of output and increased efficiency [3]. Although manufacturing companies have started to focus on production system design, many find it difficult to coordinate the production system design process and work in a structured and systematic way $[4,5]$. There are numerous explanations for the difficulties in production system design. It has been argued for example that the nature of the production system design process is not well defined, i.e. there are many different definitions and interpretations of the process and work activities involved [6]. Part of the reason is that companies have focused on the product development because they

B. Grabot et al. (Eds.): APMS 2014, Part III, IFIP AICT 440, pp. 100-107, 2014.

(C) IFIP International Federation for Information Processing 2014 
saw it as a way to achieve competitive advantages, while the production system development process is seldom seen as a means to achieve the best possible production system [7]. Thus, although the term development process is well known in manufacturing companies, it is usually applied in the product development and not in the production system required to produce the products. It is, however, important to note that the design of production systems is both a technically challenging and organisationally complex activity on its own right, and the context where it operates is more multifaceted than is commonly described in the simultaneous-engineering literature [8]. As a result, the design of production systems needs to trigger separate control and coordination of the specific set of activities required to move the project through the development process from idea to detailed design.

Overall, it can be concluded that the design of production systems is challenging but previous research provides only limited insights and guidance for managers into how those challenges can be handled. Recent studies in the area of production system design confirm that production system development generally takes place rather ad hoc and without having a long term plan $[9,10]$. The potential of gaining a competitive edge by improving the way the production system is designed is hence ignored. It is a clearly shown that it is in the early phases of production system design where the most important decisions are made. If the production system is not designed in a proper way, this will eventually end up with disturbances and problems during serial production. The result is evidently low capacity utilization, high production cost and hence low profitability. The more resources that are established early in the process, the more opportunities there are to influence the production system design [11]. The purpose with this paper is therefore to describe how to work and what activities to focus on in early phases of production system design by proposing a structured production system design model focusing on the early phases which can be applied by practitioners and academics. The results presented in this paper is a step towards a formalized production system design model offering improved understanding of how the design of production systems can be improved.

\section{Frame of Reference}

To succeed in production system design, dedication is required as well as a shift in attention from the operations phase to the under-utilized potential of the design of production systems. Although earlier research has contributed to improved knowledge about production system design and development [e.g. 11, 12, 13-16] there is still no agreement on the approaches to use in industry. When summarizing the approaches described in literature a number of stages and activities could be distinguished, Figure 1 where the design process should be considered as an iterative, cyclic process affected in its execution by each project context [13]. In a production system design process the problem is normally defined in an initial stage, where the project is initiated and defined in terms of e.g. project leader, budget, and time plan. Thereafter, an analysis of the background including present as well as future production systems and products including market research and environmental requirements is made. Based 
on this, objectives for the production system are formulated. The detailed design subsequently includes first designing conceptual production system alternatives. These early phases are focused on in this paper. The alternatives are thereafter evaluated in order to choose one final solution. The chosen production system is finally designed in detail.

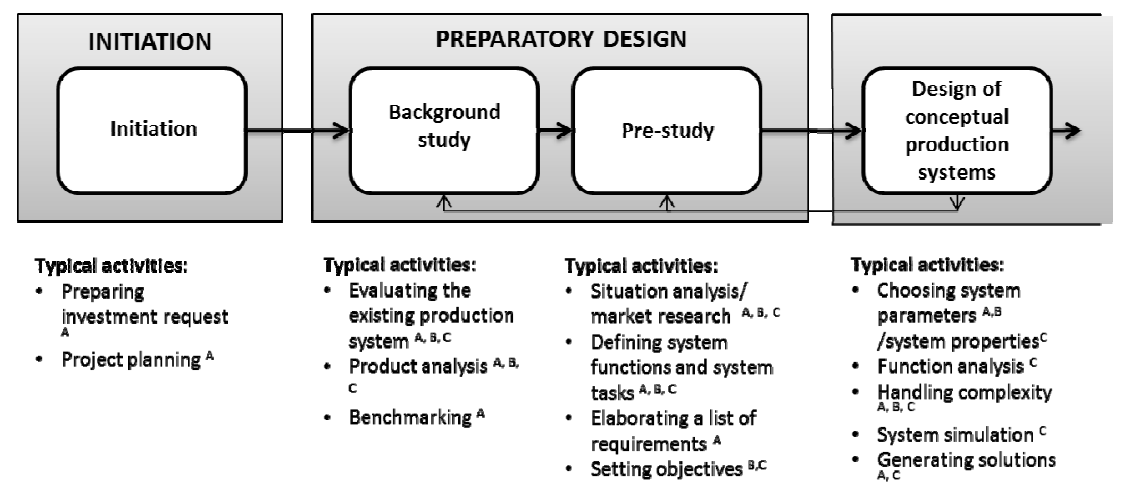

A: [7], B: [13], C: [17]

Fig. 1. Typical activities carried out in early phases of production system design

The production system design process can be considered as a part of the new product development process. Prior research on product development best practices highlights that successful projects follow a formalized and structured cross-functional stage-gate model for the product development process [17]. A structured and systematic production system design process should tell what should be done and when, what techniques and tools will be needed at each stage, what information needs to be collected, and what the output or result of each stage would be [18]. A framework should include both prescriptive and explanatory elements. While the prescriptive elements assist practitioners to carry out activities in a certain way, the explanatory elements refer to how things are perceived [19]. A framework useful for practitioners should consist of a number of logically sequential steps that support a structured work approach to the decision making process [19]. A useful framework need also to be simple to be widely used by engineers, efficient with minimum trial-and-error actions and versatile to be applicable in different situations [20]. Based on the summarized phases and activities in Figure 1. these requirements are inadequately met. A study evaluating the usability of the structured production system design process proposed by Bellgran and Säfsten [7] showed that the usage leads to increased learnability, efficiency, effectiveness, and satisfaction [21] and the contribution was largest in the early phases of the production system design process by putting emphasis on the planning and providing a structure to follow. Thus, focus on early phases is consequently crucial and worth to be highlighted. 


\section{$3 \quad$ Research Methodology}

Data was collected by the case study methodology [22] where each case represented a production system design project. The cases had an embedded design where the project was studied and the embedded unit of analysis was the production system design process including both the actual process and the documented models that were used. All cases were selected based on theoretical sampling with the goal of extending the emergent theory [23]. Six production system design projects were studied in three real-time case studies and three retrospective case studies at four different large global manufacturing companies. All interviews were recorded and transcribed. To enhance validity, real-time studies were combined with retrospective studies [24]. Through real-time studies post-rationalization was avoided, thus increasing internal validity. Data was gathered by semi-structured interviews, observations and document studies [22], Table 1.

Table 1. Information of case studies

\begin{tabular}{|c|c|c|c|}
\hline Case study & $\begin{array}{l}\text { Type and } \\
\text { Duration }\end{array}$ & Data Collection Techniques & $\begin{array}{l}\text { No interviews (single/group) } \\
\text { Duration [min] }\end{array}$ \\
\hline Case A & Real time & $\begin{array}{l}\text { Observations, Documentations } \\
\text { Interviews }\end{array}$ & $\begin{array}{l}\text { Face to face, } 10(10 / 0), \\
40-90\end{array}$ \\
\hline Case B & Retrospective & Documentation, Interviews & $\begin{array}{l}\text { Face to face, } 2(1 / 1) \\
65-76\end{array}$ \\
\hline Case C & Retrospective & Interviews & $\begin{array}{l}\text { Face to face, } 3(3 / 0) \\
63-72\end{array}$ \\
\hline Case D & Retrospective & $\begin{array}{l}\text { Observations, Documentations } \\
\text { Interviews }\end{array}$ & $\begin{array}{l}\text { Face to face, } 6(6 / 0) \\
46-85\end{array}$ \\
\hline Case E & Real time & $\begin{array}{l}\text { Observations, Documentations } \\
\text { Interviews }\end{array}$ & $\begin{array}{l}\text { Face to face, } 8(8 / 0) \\
30-80\end{array}$ \\
\hline Case F & Real time & $\begin{array}{l}\text { Observations, Documentations } \\
\text { Interviews }\end{array}$ & $\begin{array}{l}\text { Face to face, } 7(7 / 0) \\
45-107, \text { Telephone, } 1(0 / 1), 72\end{array}$ \\
\hline
\end{tabular}

Before the study started the research design was carefully described and discussed with the representatives of the company. The role of the researcher varied due to the combination of real-time and retrospective studies. In case study A, E, and F one of the researchers was present at the site during one-three months to follow the production system design project. Observations were made at production system design meetings and daily contact was maintained with the production system design team. Before and after the visit at the site, contact was kept with key persons in the production system design team. As an initial activity in all the case studies, semi-structured interviews were carried out based on an interview guide which was sent to the respondents beforehand. Respondents involved in the production system design projects were identified at different levels in the organization, such as vice president R\&D, strategic operations managers, operations managers, project managers, industrial engineers, and production engineers. Before an interview started, the terminology used 
was presented to the respondents in order to avoid misunderstandings. All initial interviews were recorded and transcribed. After the interviews were conducted relevant documentation was collected, such as project management models, production system design support, support for requirement specifications, and checklists and support used by individuals, all of which were made fully available. In all cases an on-going dialogue was held with involved key persons until rich descriptions of the single cases were achieved [22]. Observations were carried out including attendance on project meetings and development activities in the project as well as at one meeting with the system supplier. Field notes were carefully written through the whole case study [22], by which all activities were documented concerning what activity was done, how it was done, when it was done, and what people were involved.

\section{$4 \quad$ Empirical Findings}

The case studies showed that the production systems were designed according to structured stage-gate models including seven stages or phases including (1) initiation, (2) project definition/pre-study, (3) concept study, (4) detailed design and final development, (5) implementation/industrialization and commercialization, (6) followup/launch, and (7) disposal. The models used were mainly focused on product design but did also include a few activities related to the design of production systems. However, the process gave limited support to production system design. None of the stagegate models in the cases included all activities that needed to be carried out when designing the production system. In addition to the stage-gate models additional support was used. This support was either individual or used by whole organizations. Individual support included e.g. individual checklists that consisted of important issues to remember throughout the production system design process and were used by the production engineers. Support more widely used often included models for requirement specifications. Several of the design activities were undertaken based on the production engineers' skills. In all cases except Case A the projects were carried out by a project leader derived from product design. In Case A the project had two equal project leaders, one responsible for product design and the other one responsible for the industrialization including all activities related to production system design. In the cases were the project leader derived from product design there was a strong focus on product design related issues. In all projects a knowledge existed that production system design should be integrated with product design and the production engineers were part of the project team from the early start to have the possibility to affect the product design. However, product design engineers were not required to give feedback to the production system concept. In reality production engineering was not represented in the initial two phases, i.e. initiation and project definition for the overall new product development project.

Several of the projects that were studied had a lack of in-house competence in design of production systems, i.e. there were few production engineers or industrial engineers. Further, the production system engineer's often prioritized problems occurred in the running production. The production engineer normally had the main part 
of the responsibility and did not work in a group of diverse competences as in the product development teams. This resulted in less priory on production system design activities that were not absolutely necessary to do in that point of time. To strengthen production system design competence, external equipment suppliers were often used for production system design. The external equipment suppliers were involved in the concept study or the detailed design. This often resulted in a lack of long term view, a system not clearly founded in the manufacturing strategy and a lack of knowledge among the production personnel after system implementation.

\section{$5 \quad$ Production System Design Model}

As described in literature a design process should tell what should be done and when, what techniques and tools will be needed at each stage, what information needs to be collected, and what the output or result of each stage would be [18]. Based on empirical and theoretical data a production system design model is proposed. An overview of the proposed model is described in Figure 2.

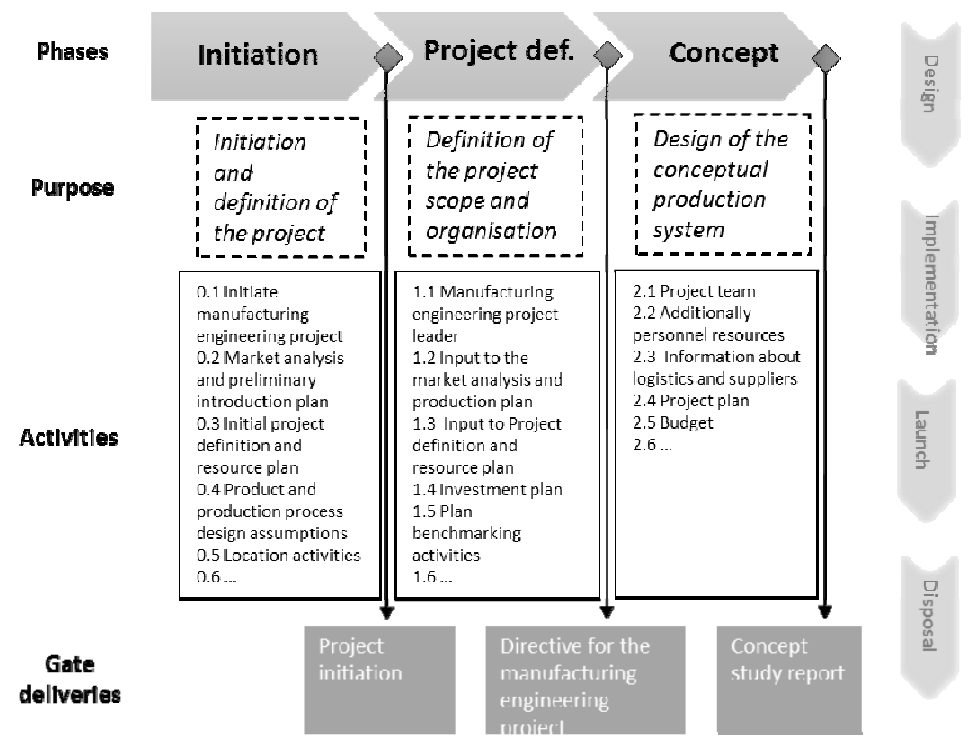

Fig. 2. Production system design model describing the earlier phases

In the initiation phase the project should is initiated and clearly defined by either the manufacturing engineering department (rationalization, replacement, quality, safety, environment etc.), the product development projects (new or changed products), or by the strategy board (Capacity, insourcing etc.). After the project is initiated the project scope and the organization should be defined. Projects conducted by project leaders derived from product design where production system design was not equal $[9,10]$ was a tendency showed in the case studies. The fact that there often was a lack 
of production engineers and the running production was prioritized instead of production system development $[9,10]$ was also obvious. To compete with production and in order to successfully design production systems it is crucial to create a project organization with all necessary competences early in the project. It was found successful to have a project leader responsible for production system design who is equal to the project leader responsible for product design to create a balance between product development and production system development. Time and resources are needed in order to focus on production system design and work in a cross functional team. In this phase commission directive should also be formulated and signed by steering committee which include scope, demand and goals of the manufacturing engineering project.

The conceptual design is a crucial project phase for the production system since in the early phases the decision space is often large while the cost for changes is low [11]. To put effort on the conceptual design and the requirement specification will keep the overall costs down in the long run. Based on commission directive the preliminary concept is formulated in details including e.g. time plan, layout, budget, and capacity and machine utilization. This ends up in a concept study report including all information needed to design the production system in detail.

\section{Conclusions}

The purpose with this paper was to describe how to work and what activities to focus in early phases of production system design by proposing a structured production system design model focusing the early phases which can be applied by practitioners and academics. There is a lack of focus on production system design and projects are mainly owned by as well as focused on product design. Based on a detailed production system design model activities were specified resulting in the concept study report. The design model should be used as a complement to already established product development models. The results presented in this paper was a step toward a formalized production system design model offering improved understanding of production systems design process including how it is carried out, who is involved, etc.

\section{References}

1. Wiendahl, H.-P., Heger, C.L.: Justifying Changeability: A Methodical Approach to Achieving Cost Effectiveness. International Journal for Manufacturing Science and Production 6(1-2), 33-39 (2004)

2. Westkämper, E.: New Trends in Production. In: Dashchenko, A.I. (ed.) Reconfigurable Manufacturing Systems and Transformable Factories, pp. 15-26. Springer, Heidelberg (2006)

3. Hayes, R., et al.: Operations, Strategy, and Technology: Pursuing the Competitive Edge. Strategic Direction. John Wiley \& Sons, Hoboken (2005)

4. Bruch, J., Bellgran, M.: Characteristics affecting management of design information in the production system design process. International Journal of Production Research 51(11), 3241-3251 (2013) 
5. Rösiö, C., Säfsten, K.: Reconfigurable Production System Design - theoretical and practical challenges. Journal of Manufacturing Technology Management 24(7) (2013)

6. Cochran, D.S., et al.: A decomposition approach for manufacturing system design. Journal of Manufacturing Systems 20(6), 371-389 (2001-2002)

7. Bellgran, M., Säfsten, K.: Production Development: Design and Operation of Production Systems. Springer, London (2010)

8. Pisano, G.P.: The Development Factory: Unlocking the Potential of Process Innovation. Harvard Business Review Press, Boston (1997)

9. Bruch, J.: Management of Design Information in the Production System Design Process. In: School of Innovation Design and Engineering, Mälardalens University (2012)

10. Rösiö, C.: Supporting the Design of Reconfigurable Production Systems. In: School of Innovation Design and Engineering, Mälardalen University (2012)

11. Blanchard, B.S., Fabrycky, W.J.: Systems Engineering and Analysis, 3rd edn. PrenticeHall, Inc., Upper Saddle River (1998)

12. Bennett, D.J., Forrester, P.L.: Market-Focused Production Systems: Design and Implementation. Prentice Hall International, Hemel Hempstead (1993)

13. Wu, B.: Manufacturing Systems Design and Analysis: Context and techniques, 2nd edn. Chapman \& Hall, London (1994)

14. Bellgran, M.: Systematic Design of Assembly Systems: Preconditions and Design Process Planning. In: Department of Mechanical Engineering. Linköping University, Linköping (1998)

15. Kulak, O., Durmusoglu, M.B., Tufekci, S.: A complete cellular manufacturing system design methodology based on axiomatic design principles. Computers and Industrial Engineering 48(4), 765-787 (2005)

16. Rampersad, H.K.: Integrated and Simultaneous Design for Robotic Assembly. Wiley Series in Product Development: Planning, Designing, Engineering. In: Cross, N., Roozenburg, N. (eds.). John Wiley \& Sons, Nwe York (1994)

17. Griffin, A.: PDMA Research on New Product Development Practices: Updating Trends and Benchmarking Best Practices. Journal of Product Innovation Management 14(6), 429-458 (1997)

18. Love, D.: The design of manufacturing systems. In: Warner, M. (ed.) International Encyclopedia of Business and Management, pp. 3154-3174. International Thomson Business Press, London (1996)

19. McIvor, R.: A practical framework for understanding the outsourcing process. Supply Chain Management: An International Journal 5(1), 22-36 (2000)

20. Houshmand, M., Jamshidnezhad, B.: An extended model of design process of lean production systems by means of process variables. Robotics and Computer-Integrated Manufacturing 22(1), 1-16 (2006)

21. Arnesson, F., Bengtsson, J.: Usability Evaluation of a Production System Development Framework. In: School of Engineering 2012. Jönköping University, Jönköping (2012)

22. Yin, R.K.: Case Study Research: Design and Methods, 4th edn. SAGE, Thousands Oaks (2009)

23. Eisenhardt, K.M.: Building Theories from Case Study Research. Academy of Management Review 14(4), 532-550 (1989)

24. Leonard-Barton, D.: A Dual Methodology for Case Studies: Synergistic Use of a Longitudinal Single Site with Replicated Multiple Sites. Organization Science 1(3), 248-266 (1990) 